\title{
FACTORS INFLUENCING STEM CAREER INTERESTS IN HIGH SCHOOL STUDENTS WITH DISABILITIES
}

\section{CHARITY NEEJIDE ONYISHI \& MAXIMUS MONAHENG SEFOTHO}

Department of Educational Psychology, University of Johannesburg, South-Africa

\begin{abstract}
Studies in science, technology, engineering and math (STEM) have focused considerably on issues related to underrepresented groups' participation in STEM disciplines. Students with disabilities are among the groups that are underrepresented in STEM careers worldwide. The problem is of great concern as persons with disabilities are rarely found in stem career fields. This study investigated whether and to what extent the selected factors predict STEM career interest in students with disabilities in senior secondary schools in Nigeria. A quantitative approach was utilized in the study, using descriptive research design. Data were collected using a demographic questionnaire, three subscales were of the interest in STEM career questionnaire developed by Halim et al., (2018), and stem Career Interest Survey (STEMCIS) (Kier et al., 2014). Data analyses were conducted using descriptive statistic and regression analyses. Descriptive statistics showed that participants recorded high score in social influences on STEM career interests (Mean= 3.42, $S D=.69$ ) and poor perception of STEM career (Mean=2.45, SD=.72)among students with disabilities. Regression analysis showed that interest in STEM career fields, such as science, technology, engineering and mathematics related careers were predicted by social influences, perception of STEM career and STEM self-efficacy in the participants. It was concluded that social influences, perception of STEM careers and STEM self-efficacy were the major determinants of STEM career interests in students with disabilities. These findings can be used to inform career counseling and research.
\end{abstract}

KEYWORDS: Career Developments, Career Interests, Disabilities \& STEM

Received: Mar 23, 2021; Accepted: Apr 13, 2021; Published: Jun 07, 2021; Paper Id.: IJMPERDAUG20211

\section{INTRODUCTION}

The development in the global economy in the $21^{\text {st }}$ century is increasingly becoming dependent on science, technology, engineering, and mathematics (STEM)(da Silva Cardoso et al., 2013; Onyishi \& Sefotho, n.d.; Waite $\&$ McDonald, 2019). The globalized fiscal revolutionization, information sciences and technology development, changes in employability standards, make it imperative for STEM career development in all students irrespective of any perceived limiting factors. STEM workforce is generally having a shortage of manpower, suggesting increased employment opportunities in the STEM fields for graduates who complete STEM majors at college (Lee, 2011a). However, from global perspectives, the number of students catching interests in STEM careers are declining across the board(Archer et al., 2012; Aschbacher et al., 2010; Yerdelen et al., 2016). Students with disabilities are among the underrepresented groups in STEM majors and career (Peng et al., 2012). While non-STEM jobs are gradually overtaken by robotics and artificial intelligence, there is an increasing need for STEM professionals in the workforce across the world(Tuijl \& Van, 2016), thus, gradually forming the basis for employability and job successes (Onyishi \& Sefotho, 2019; Waite \& McDonald, 2019) Thus, graduating, and or taking a career path in STEM fields is a viable way of overcoming the risk of unemployment and hope and certainty for career success(Izzo et al., 2011; McDonald 
\& Waite, 2019; Mcmahon, 2013).

In spite of the overarching and promising nature of STEM to career development and career success, research has indicated that persons with disabilities are among the minority groups who are underrepresented in a STEM career (Dunn et al., 2012; Izzo et al., 2011; Onyishi \& Sefotho, 2019). Though evidence tends to suggest that students with disabilities (SWD) are able to complete STEM majors in the university and or achieve STEM careers(Schreffler et al., 2019), only a few of learners in this category offer STEM related courses or take up STEM related careers (Estrada et al., 2018; Izzo et al., 2011; Mcmahon, 2013). This tends to limit employment opportunities for Students With Disabilities (SWD) and as such may be one of the productive measures for reducing poverty among disabled populations(McGunagle \&Zizka, 2020; Onyishi \& Sefotho, 2019). However, students with disabilities are less likely to enroll in, and complete STEM related course or careers than their non-disabled population (Burgstahler \& Ladner, 2006; Lee, 2011; McMahon, 2013; Plasman \& Gottfried, 2018). The under representation of students with disabilities in STEM careers often does not mean that such students are always incapable of excelling in STEM career fields(Kauffmann et al., 2009). Hence, researchers worried about finding out the reasons behind students choosing STEM career (da Silva Cardoso et al., 2013; Kauffmann et al., 2009; Tuijl\& Van, 2016).

There are five categories of goals for science education: scientific knowledge, application of scientific methods, responsible decision-making for society, development of personal understanding, and career awareness (Bybee \& Pruitt, 2017). In order to stimulate economic growth and enhance innovation, there are increasing global efforts towards increasing students' interest in STEM careers. It is recommended that efforts to get the interest of students with disabilities in STEM majors and careers(Brand et al., 2013; Lee, 2014; Rule et al., 2009). Given that development of strong and real career interests begins at secondary school level, mainly because students are becoming aware of their academic strengths, the narratives of students with disabilities may be peculiar. This could be that such students, in addition to making appropriate career choices and developing interest, also battle with disability identity, which may be of strong impact on career decisions.

A good number of research studies have been conducted in this area (Estrada et al., 2018; Kauffmann et al., 2009; McDonald \& Waite, 2019; Mcmahon, 2013; Onyishi \& Sefotho, n.d., 2019; Peng et al., 2012; Tuijl \& Van, 2016). Evidence indicate that a major problem is that students with disabilities diverse obstacles to STEM career participation depending on the types of their disabilities. For instance, it has been found that students with physical disabilities in secondary schools have limited access to facilities in science and engineering environments compared to those with other disabilities and those without disabilities (Lee, 2011a, 2014). Further studies show that teachers often make little effort to accommodate students with disabilities in STEM, resulting in limited educational readiness for STEM careers among such students(Burgstahler\&Ladner, 2006; da Silva Cardoso et al., 2013; Dunn et al., 2012; Estrada et al., 2018; Halim et al., 2018; van Tuijl\& van der Molen, 2016).

On the other hand, students' personal factors such as prior experiences with STEM learning, prior achievements and self-efficacy in STEM fields (Estrada et al., 2018; Lee, 2011b; Mcmahon, 2013; Onyishi \& Sefotho, 2019). Additionally, students with disabilities tend to face a barrier to access to STEM education and this affects their interest in STEM careers (da Silva Cardoso et al., 2013; Dutta et al., 2015). This is especially critical in Nigeria as students with disabilities experience additional challenges in STEM due to lack of resources and cultural attitudes towards disabilities (Adelakun, 2017; Lee, 2011a; Onyishi \& Sefotho, 2019; Osokoya \& Junaid, 2015). The stigma associated with disability in Nigeria, coupled with lack of social support, disability identity, (a person's sense of self as an individual with a disability), could also have a dual influence on students with disabilities choosing a career in STEM fields. However, it is not clear how such identities affect 
career interest in secondary school students with disabilities in Nigeria.

Further, as persons with disabilities in Nigeria, are making head-over-heels into the formal education system persons with disabilities are increasingly enrolling and graduating from university education, the majority are majoring in Arts, Social Sciences and Education faculties (Ebifa et al., 2018; Onyishi \& Sefotho, 2019). Their being in arts and social sciences more than STEM fields indicate that there are underlying constraints to their STEM aspiration and interests (Onyishi \& Sefotho, 2019). Ebifa et al., (2018) suggested that both the students with disabilities and the society feel that their impairments due to deformities will undermine their abilities to work in STEM fields. To counter such negative perceptions about disabilities Nigerians with disabilities decree of 1993, proposed that $10 \%$ of the government workforce should be reserved for persons with disabilities. Out of these jobs are those in STEM fields, thus calling for increased STEM majors and career paths.

Additionally, despite the calls for consideration of persons with disabilities' underrepresentation in STEM in Nigeria, only negligible research has examined what is responsible for their poor STEM aspirations specifically. Empirical studies so far in this area dealt with finding out how mathematics self-efficacy influences career inclination in students with disabilities(Onyishi \& Sefotho, 2019). Another related study looked at career aspiration in visually impaired students (Ebifa et al., 2018), where it was found that students with visual impairments rarely take a career in STEM field in the area. It is not clear what factors account for this dismal condition of poor STEM career aspiration in students with disabilities in Nigeria.

Studies indicate that the explanatory model for students with disabilities undertaking STEM career is due to the social cognitive career theory (SCCT), which considers both the learners' individual difference as well as the social environment and behavioral factors(da Silva Cardoso et al., 2013; Lent et al. 2000). This theory has been used in previous studies to examine the factors that affect interest in STEM careers (Kier et al., 2014; Nugent et al., 2015; Sahin et al., 2015). Four crucial factors affecting STEM careers, (environmental factors, STEM self-efficacy, perception of STEM careers and interest in STEM careers) are considered under the SCCT. Hence, the theory sees STEM career aspirations and choices as outcomes of personal factors including the environment and behavior(Gottfried et al., 2016; Maltese \& Tai, 2011). This theory investigates social factors and self-efficacy as determinants of action (Kier et al., 2014). Hence, social/environmental factors of career interests in this respect includes parental, teachers and peer influences, as well as media influences on the students, while the behavioural factors may include the learning experiences (classroom learning activities, outdoor classroom activities), perception of STEM careers and STEM self-efficacy(da Silva Cardoso et al., 2013; Dutta et al., 2015; Halim et al., 2018).

Thus, the present study sought to investigate the factors influencing STEM career interest in a sample of high school students with disabilities. We then propose that the career interests of students with disabilities will be significantly predicted by social influence factors, STEM self-efficacy and perception of a STEM career.

\section{MATERIAL AND METHOD}

\section{Design}

This study utilized a descriptive approach capitalizing on quantitative data collected from a cross-sectional study. 


\section{Participants and Sampling}

The researcher purposively sampled 20 inclusive oriented secondary schools in the South-East geopolitical zone, Nigeria. A total of 572 SWD in senior secondary SS 1-3 in all the sampled inclusive oriented senior secondary schools in South-East Nigeria, who met the inclusion criteria, participated in the study. Inclusion criteria included: i) the participants must sign a written consent to participate in the study; ii) must be in grade levels, senior secondary 1-3; iii) has been identified with at least one type of disability. Those who did not meet the inclusion criteria were excluded. For demographic variables of the participants, see figure 1 .

3.1.2. Table 1: Participants' Demographic Characteristics

\begin{tabular}{|c|l|c|c|c|}
\hline Characteristics & & Male $(\mathbf{N}=\mathbf{3 2 3})$ & Female $(\mathbf{N = 2 4 9 )}$ & Total (N=572) \\
\hline \multirow{5}{*}{ Grade Level } & SS1 & $108(18.88 \%)$ & $100(17.48 \%)$ & $208(36.36 \%)$ \\
\cline { 2 - 5 } & SS2 & $118(21.77 \%)$ & $92(16.08 \%)$ & $210(36.71 \%)$ \\
\cline { 2 - 5 } & SS3 & $97(15.95 \%)$ & $57(9.96 \%)$ & $154(26.92 \%)$ \\
\cline { 2 - 5 } & Total & $323(56.46 \%)$ & $249(43.53 \%)$ & $572(100 \%)$ \\
\hline \multirow{5}{*}{ Disability Type } & Physical disabilities & $109(19.05 \%)$ & $86(14.04 \%)$ & $195(34.09 \%)$ \\
\cline { 2 - 5 } & LD & $53(9.26 \%)$ & $43(7.51 \%)$ & $96(16.78 \%)$ \\
\cline { 2 - 5 } & DD & $55(9.61 \%)$ & $37(6.46 \%)$ & $92(16.08 \%)$ \\
\cline { 2 - 5 } & HI & $57(9.96 \%)$ & $41(7.16 \%)$ & $98(17.15 \%)$ \\
\cline { 2 - 5 } & VI & $49(8.56 \%)$ & $42(7.34 \%)$ & $91(15.90 \%)$ \\
\hline Total & & $\mathbf{3 2 3 ( 5 6 . 4 6 )}$ & $\mathbf{2 4 9}$ & $\mathbf{5 7 2 ( 1 0 0 \% )}$ \\
\hline
\end{tabular}

Out of the 572 participants in the study, $323(56.46 \%)$ were males while $249(43.53 \%)$ were females. A total of 208 (36.36\%), including 108 (18.88\%) male and 100 (17.48\%) females were in SS1 while 210 (36.71\%), which include 118 (21.77\%) males and 92 (16.08\%) females were in SS2. 154 (26.92\%), including 97 (15.95\%) males and 57 (9.96\%) females are in SS3. Based on the type of disabilities, 195 (34.09\%) participants which include 109 (19.05\%) males and 86 (14.04\%) females have physical disabilities. 96 (16.78\%)participants, which include $53(9.26 \%)$ males and $43(7.51 \%)$ females are with learning disabilities.92 (14.33\%) participants, including 55 (9.61\%) males and 37 (6.46\%) females have Autism and other neuro developmental disorders. 98(17.15\%) participants which are 57(9.96\%) males and $41(7.16 \%)$ females have speech and, or hearing impairments. 91 (15.90\%) of the participants including 49 (8.56\%) males and $42(7.34 \%)$ females have a visual impairment.

\section{MEASURES}

The demographic Questionnaire was meant to ascertain information about the demographic variables of the participants. The respondents were required to tick the box as it is most appropriate for them in each case. Based on that, information about gender, type of disability, grade level, and age of the participants was collected.

To measure the factors influencing STEM careers in the participants, three subscales were adapted from the interest in STEM career questionnaire developed by (Halim et al., 2018). Based on this, sections C, E and F of Halim, et al., were adopted. Section C measures Social Influences on STEM Education and Careers and is made up of 11 items. Section E measures STEM Learning Self-Efficacy in 4 dimensions of science (5 items); technology (5 items), Engineering (5items) and mathematics (5 items). Section F measures the Perception of STEM Careers in 14 items, including the perception of job prospects in STEM fields and the skills needed by workers in STEM fields. Job prospects in STEM fields include the working environment in terms of safety, job satisfaction, and perception of STEM as a prestigious career, high employment opportunities, higher income, and contribution to society. The original version of this scales was measured on a scale of 10 point, ranging from 1 (Never) to 10 (Always). Halim et al., (2018) found a good psychometric quality of the scales, however, 
trial tested in original form to Nigerian secondary school students with disabilities, we found a poor reliability index of Alpha $=.45$. Consequently, the scales were adapted to 5 points. After the rescaling, the measures showed an interesting reliability index $\alpha=.88$.

Information about STEM career interest was sourced using the STEM Career Interest Survey (STEM-CIS) (Kier et al., 2014). The STEM-CIS measures STEM career interest and the effects of STEM programs on changes in student interest in STEM subjects and careers (Kier et al., 2014). The scale is measured in 5 points, ranging from Strongly Disagree (1), Disagree (2), Neither Agree nor Disagree (3), Agree (4), Strongly Agree (5). The STEM-CIS has four subscales, evaluating interest in the four fields of STEM (science, technology, engineering, and mathematics). Each subscale has 11 items in the original version, however, four items (items 1, 2, 6 and 9) in each subscale were removed because the measure self-efficacy, and social influences which has been captured in sections of Halim's scale used to measure factors influencing career interest in this study (Halim et al., 2018). For example, in mathematics subscales, item 1, (I am able to get a good grade in my math class), 2 (I am able to complete my math homework), 6 (My parents would like it if I choose a mathematics career), and 9 (I have a role model in a mathematics career) were discarded.STEM-CIS used in this study has a total of 29 items (7 items each for science, technology, engineering, and mathematics). Though the scale has been found to be of good psychometric properties (Kier et al., 2014), we further sought the reliability of the adapted version in 57 secondary school students with disabilities in Nigeria $(\alpha=.79)$.

\section{Ethical Considerations}

The researchers obtained approval to conduct this study from the research ethics committee of the faculty of Education, University of Nigeria, Nsukka. The researcher sought informed consent from the prospective participants before data collection. On that note, prospective participants who failed to sign a written consent were excluded from participating. The researcher compensated the participants in each school with a gift of STEM career guidance booklets developed and printed by the researcher.

\section{Data Collection}

The researcher, with the help of two research assistants, visited 33 general education secondary schools and four inclusive oriented secondary schools in South-East Nigeria for data collection. All the schools were Government-owned. In each school visited, the researcher collaborated with the school administration and the school counselor to identify students with all kinds of disabilities.

\section{Design and Data Analysis}

A quantitative research design was adopted for the study. Mean, standard deviation and structural Equation Model (SEM) analyses were performed to determine the extent to which each independent variable contributes to variance in the dependent variables (STEM career interest dimensions). The data were entered and analyzed quantitatively using IBM SPSS Version 25 .

\section{RESULTS}

Table 2

\begin{tabular}{|l|c|c|c|c|c|c|}
\hline \multicolumn{1}{|c|}{ Measure } & Subscale & N & Minimum & Maximum & Mean & Std. Deviation \\
\hline & & & & & & \\
\hline Social Influences & & 572 & 1.00 & 3.70 & 3.42 & .69 \\
\hline
\end{tabular}




\begin{tabular}{|l|l|c|c|c|c|c|}
\hline Perception & & 572 & 1.00 & 3.00 & 2.45 & .72 \\
\hline Self-efficacy & $\begin{array}{l}\text { Total STEM Self- } \\
\text { efficacy }\end{array}$ & 572 & .00 & 3.00 & 1.33 & .72 \\
\hline & S-Self-efficacy & 572 & .00 & 3.00 & 1.71 & .72 \\
\hline & T-Self-efficacy & 572 & .00 & 3.00 & 1.26 & .69 \\
\hline & E-Self-efficacy & 572 & 1.00 & 3.00 & 1.58 & .60 \\
\hline MTEM Career Interest & M-Self-efficacy & 572 & .00 & 3.00 & 1.45 & .72 \\
\hline & Total STEM Interest & 572 & .33 & 3.00 & 1.45 & .63 \\
\hline & S-Interest & 572 & .00 & 2.67 & 1.37 & .61 \\
\hline & T-Interest & 572 & .37 & 3.00 & 1.50 & .63 \\
\hline & E-Interest & 572 & .00 & 3.00 & 1.46 & .71 \\
\hline & M-Interest & 572 & 1.17 & 2.92 & 1.45 & .63 \\
\hline
\end{tabular}

Descriptive data in Table 2 show that participants recorded high score in social influences on STEM career interests $(\mathrm{Mean}=3.42, \mathrm{SD}=.69)$. This indicated that significant persons around persons with disabilities such as the parents, family members, teachers, friends, counselors, role models and local communities influence their career interest to a great extent. Perception of STEM career (Mean=2.45, SD=.72) was also poor among students with disabilities. This means that the perception of students with disabilities about the job prospects in STEM careers and the skills needed for working in STEM fields was low. It also indicates that their perceptions of the working environment in terms of safety, job satisfaction, STEM as a prestigious career, high employment opportunities, higher income, and contribution to society are low.

However, the data in Table 2 revealed low STEM self-efficacy in the participants (Mean= 1.33, SD=.72). This suggests that students with disabilities generally do not believe that they can successfully accomplish STEM related tasks. The table further showed a poor mean score of science self-efficacy (Mean=1.71, SD=.72), technology self-efficacy (Mean= 1.26, $\mathrm{SD}=.69$ ), Engineering self-efficacy (Mean=1.58, $\mathrm{SD}=.60)$ mathematics self-efficacy $(\mathrm{Mean}=1.45, \mathrm{SD}=.72)$. This reveals the poor self-perception of students with disabilities when it comes STEM fields.

Data in Table 2 further show that the mean total STEM career interest among students with disabilities was low (Mean= 3.45, SD=.63). Based on specific STEM fields, Science career interest was low (Mean= 1.37, SD=.61), Students with disabilities who participated in the study also rated their interest in Technology as low $(\mathrm{Mean}=1.40, \mathrm{SD}=.63)$; Engineering career interest low $(\mathrm{Mean}=1.46, \mathrm{SD}=.71)$ and Mathematics career interest were also low $(\mathrm{Mean}=1.45, \mathrm{SD}=.63)$.

Table 3

\begin{tabular}{||l|l|c|c|c|c|c|}
\hline \multirow{2}{*}{ Dependent Variable } & \multicolumn{2}{|c|}{ Independent Variable B } & $\begin{array}{c}\text { Std. } \\
\text { Error }\end{array}$ & Beta & T & $\begin{array}{c}\text { p- } \\
\text { Value }\end{array}$ \\
\hline S-Interest & Social Influences & .54 & .01 & .57 & 13.80 & .000 \\
\hline & Perception & .34 & .04 & .40 & 9.48 & .000 \\
\hline & STEM-Self-efficacy & .22 & .03 & .24 & 4.06 & .000 \\
\hline & S-Self-efficacy & .70 & .03 & .83 & 24.31 & .000 \\
\hline & T-Self-efficacy & .04 & .01 & .05 & 4.11 & .340 \\
\hline & E-Self-efficacy & .16 & .03 & .19 & 5.74 & .103 \\
\hline & M-Self-efficacy & .71 & .02 & .70 & 25.90 & .000 \\
\hline & & & & & & \\
\hline & & & & & & \\
\hline T-Interest & .65 & .08 & .72 & 15.23 & .000 \\
\hline & Social Influences & .49 & .27 & .54 & 13.72 & .000 \\
\hline & Perception & .35 & .11 & .49 & 3.15 & .002 \\
\hline & STEM-Self-efficacy & .04 & .04 & .05 & 1.31 & .676 \\
\hline & S-Self-efficacy & 1.03 & .77 & 1.12 & 14.21 & .000 \\
\hline & T-Self-efficacy & .91 & .65 & .97 & 13.91 & .000 \\
\hline
\end{tabular}




\begin{tabular}{||l|l|c|c|c|c|c|}
\hline & M-Self-efficacy & .15 & .04 & .30 & 3.217 & .001 \\
\hline & & & & & & \\
\hline & Social Influences & .95 & .07 & .95 & 17.29 & .000 \\
\hline & Perception & .79 & .13 & .88 & 12.20 & .000 \\
\hline & STEM-Self-efficacy & .46 & .14 & .48 & 3.28 & .001 \\
\hline & S-Self-efficacy & .01 & .01 & .02 & .84 & .372 \\
\hline & T-Self-efficacy & .03 & .07 & .05 & .41 & .646 \\
\hline & E-Self-efficacy & .60 & .03 & .60 & -19.53 & .000 \\
\hline & M-Self-efficacy & .61 & .07 & .67 & 2.61 & .000 \\
\hline & & & & & & \\
\hline M-Interest & Social Influences & .67 & .28 & .75 & 15.18 & .000 \\
\hline & Perception & .47 & .52 & .53 & 2.80 & .000 \\
\hline & STEM-Self-efficacy & .39 & .19 & .80 & 5.51 & .000 \\
\hline & S-Self-efficacy & .60 & .03 & .60 & 19.53 & .000 \\
\hline & T-Self-efficacy & .17 & .15 & .18 & 1.50 & .134 \\
\hline & E-Self-efficacy & .54 & .03 & .63 & 6.79 & .000 \\
\hline & M-Self-efficacy & .49 & .02 & .57 & 6.66 & .000 \\
\hline & & & & & & \\
\hline
\end{tabular}

Data in Table 3 revealed that science interest was predicted by social influences $(B=.54, \beta=.57, p=.000$ ), perception of STEM career ( $B=.34, \beta=.40, p=.000$ ), and STEM self-efficacy $(B=.22, \beta=.24, p=.000)$. This is to say that social influences, such as parental teachers and peer influences account for about $54 \%$ variation in science career interests of students with disabilities. On the other hand, 34\% of differences in career interest in the participants is determined by how they perceive STEM career, while $22 \%$ is linked to how confident they are, that they can accomplish goal in STEM fields (STEM selfefficacy. Considering the domain-specific self-efficacy, science career interest was significantly predicted by science selfefficacy ( $B=.70, \beta=.83, p=.000)$, and mathematics self-efficacy $(B=.71, \beta=.70, p=.000)$, but Technology self-efficacy $(B=.04$, $\beta=.05, p=.340)$ and Engineering self-efficacy $(B=.16, \beta=.19, p=.103)$ were not significant predictors.

Participants' interest in technology careers was significantly predicted by social influences ( $B=.65, \beta=.72, p=.000)$, perception of STEM career $(B=.49, \beta=.54, p=.000)$, and STEM self-efficacy $(B=.39, \beta=.45, p=.001)$. These suggest that about $65 \%$ differences in technology career interest in the participants is accounted for, by social influences; perception of STEM careers accounts for 49\% variation in technology career interest and STEM self-efficacy account for about 39\% variation in participants' technology interest. Furthermore, technology career interest was significantly predicted by technology self-efficacy $(B=1.03, \beta=1.12, p=.000)$, Engineering self-efficacy $(B=.91, \beta=.97, p=.000)$ and mathematics selfefficacy $(B=.15, \beta=.30, p=.001)$, but not science self-efficacy $(B=.04, \beta=.05, p=.676)$ were not significant predictors.

Interest in engineering careers is significantly predicted by social influences $(B=.95, \beta=.95, p=.000)$, perception of STEM career $(B=.79, \beta=.88, p=.000)$, and STEM self-efficacy $(B=.46, \beta=.48, p=.001)$. These suggest that about $95 \%$ differences in engineering career interest in the participants is a product of social influences; $79 \%$ variation in engineering career interest is a product of students' perception of STEM careers while about $46 \%$ variation in participants' engineering interest is due to their STEM self-efficacy. Furthermore, engineering career interest was significantly predicted by engineering self-efficacy $(B=.60, \beta=60, p=.000)$, and mathematics self-efficacy $(B=.61, \beta=.67, p=.000)$, but not science selfefficacy $(B=.01, \beta=.02, p=.372)$, or technology self-efficacy $(B=.03, \beta=.05, p=.000)$.

Interest in math-related careers is significantly predicted by social influences $(B=.67, \beta=.75, p=.000)$, perception of STEM career $(B=.47, \beta=.53, p=.000)$, and STEM self-efficacy $(B=.39, \beta=.40, p=.001)$. These suggest that about $67 \%$ differences in mathematics career interest in the participants is a product of social influences; $39 \%$ variation in mathematics 
career interest is a product of students' perception of STEM careers, while about 39\% variation in participants' mathematics interest is due to their STEM self-efficacy. Furthermore, mathematics related career interest was significantly predicted by science self-efficacy $(B=.60, \beta=60, p=.000)$, engineering self-efficacy $(B=.54, \beta=.63$, $p=.000)$, and mathematics self-efficacy $(\mathrm{B}=.49, \beta=.57, \mathrm{p}=.000)$, but not technology self-efficacy $(\mathrm{B}=.17, \beta=.18, \mathrm{p}=.134)$.

\section{DISCUSSIONS}

The underrepresentation of persons with disabilities in STEM majors and careers has been recognized as a global issue and a challenge to all stakeholders in disability development and research. There is an increasing need to find out factors that are responsible for STEM career interest in students with disabilities. The current study sought to investigate the factors influencing STEM career interest in students with disabilities. Results revealed high social influences on STEM career interest among the participants. Low perception of science career was also revealed, indicating that the participants perceive STEM careers to be positive and prestigious. There was generally poor self-efficacy and poor interest in STEM career among the participants. Regression analysis showed that interest in STEM career fields, such as science, technology, engineering and mathematics related careers were predicted by social influences, perception of STEM career and STEM self-efficacy in the participants.

This outcome is interesting, yet not surprising, given the social cognitive career theory, which states that those career aspirations and choices are a result of personal factors which involve not only the behavior but also the environment(Halim et al., 2018; Kier et al., 2014; Maltese \& Tai, 2011). Thus, a discussion of results will be made along with the following: Social influences on career interest of students with disabilities; the influence of STEM perception on students with disabilities' interest in STEM career fields; and the influence of STEM self-efficacy on interest in STEMrelated careers.

\section{Social Influences on STEM Career Interest of Students with Disabilities}

The present study found that social factors tend to have determining influence on STEM career interest of students with disabilities. This social factor in this study was measured according to (Halim et al., 2018) who conceived social influence as the influences of significant persons around the individual, such as parents, family members, teachers, friends/peers, counselors, role models and local communities. The findings of this study concur with the prior studies which found that social factors are influential in career aspiration and career choices of students(Aschbacher et al., 2010; da Silva Cardoso et al., 2013, 2013; Dutta et al., 2015; Tillman, 2015, 2015). For instance, studies consistently show that parents' encouragements are critical for fostering better academic work, positive school attitudes and higher career aspirations in normal students' population (Halim, et al., 2017). The outcome of the present study indicates that the same is true of students with disabilities. The likelihood of a student with a disability choosing STEM related career is a product of parental encouragements and supports (Kauffmann et al., 2009; Tillman, 2015). Career development of students with intellectual disabilities depends on many factors including, family influence, social interactions and academic excellence (Viola, \& Daniel, 2019). The same study found that parental perceptions play a role in childrens' education, vocation choice and behavior towards career choice. Furthermore, studies have also identified the importance of peer influence on career choices and decision making among students without disabilities (Halim et al., 2018; Joel, 2017; Quinter \& Edwards, 2011). Supporting these earlier research, the present study extends insight to the fact that the social influences of peers could determine the STEM interest of students with disabilities. Additionally, teachers and counselors are a significant factor in the career interests of students with disabilities (Kimani et al., 2013). Hence, it is not unexpected that social influences significantly predicted STEM career 
interest in students with disabilities.

\section{Influence of STEM Perception on STEM Career Interest of Students with Disabilities}

Perception of STEM careers is the awareness of job prospects in STEM fields and the skills needed to work in STEM fields. Perception of STEM career was found in this study to predict career interest in all dimensions of STEM fields. This finding agrees with Morgan, Isaac and Sansone (2001), who found that perception of the interestingness of a career positively predicted the likelihood of career choice. This is consistent with the findings of research on middle school students showing that students' occupational preferences and career aspirations are strongly linked to their images and perceptions of particular occupations. Further, it has been suggested that holding false perceptions of scientists can prohibit students from pursuing science, emphasizing the importance of correcting these perceptions (Zeldin \& Pajares, 2000). Thus, student's basic knowledge of what a particular STEM profession is and involves has been found to be linked to their interest in pursuing that area of study (Robinson \& Kenny, 2003).

Additionally, awareness of the requirements for STEM skills, qualifications, requirements and job prospects are likely factors tor students' interest in careers (Holman \& Finegold, 2010; Wyss, Heulskamp, \& Siebert, 2012). Students' basic knowledge of career requirements, for example, the skills needed and the job prospect, can significantly impact their perception of what a particular STEM profession entails (Franz-Odendaal, Blotnicky, French, \& Joy 2016; Wyss, Heulskamp, \& Siebert, 2012). In their research of 568 middle school children, Franz-Odendaal et al. (2016) found that students will not follow careers that they are not familiar with, thus perception of career. Wyss, Heulskamp, and Sibert (2012) further argued that when students have negative views of STEM professions, the students may be left out in developing interest in the process during formal schooling. The present study has helped to clarify issues around poor STEM career interest in students with disabilities, indicating that pore perception and awareness of students with disabilities about STEM career prospects and requirements could account for the underrepresentation of students with disabilities in STEM fields. The study shows that students' interest in particular occupations is linked to their perceptions of the career (Wyss, Heulskamp, \&Siebert, 2012).

\section{Influence of STEM Self-Efficacy on Interest in STEM-Related Careers among Students with Disabilities}

Self-efficacy is the belief in one's capabilities to organize and execute the courses of action required to produce given attainment(Jenson et al., 2011).In this present research, self-efficacy for STEM refers to the student's beliefs about their ability to perform in science, technology, engineering and mathematics respectively. According to Tracey (2010), interest and self-efficacy very important in identifying and determining one's possible career choice. Self-efficacy has been found to be an important factor in the development of career interest, especially in STEM fields (Burwell-Woo, Lapuz, Huang, \& Rentsch, 2015; Rittmayer\& Beier, 2008). As regard students with disabilities, mathematic self-efficacy has been found to predict STEM career inclination (Ebifa et al., 2018; Onyishi \& Sefotho, 2019). Hence, a prior study has identified poor STEM self-efficacy in students with disabilities (Jenson et al., 2011). A student's sense of self influences his or her perceptions of self-efficacy. Hence, it is possible that what undermines STEM self-efficacy of students with disabilities in their self-identity. To increase the interest of students with disabilities in STEM career, perception of self and perception of STEM career need to be harmonized, identifying the capabilities in students with disabilities that could support career path in STEM fields. 


\section{Implications for School Psychologists}

In an effort to increase the number of students with disabilities who will pursue STEM study and careers, counselors and school psychologists need to increase student awareness of a variety of STEM careers early in school years. Parents and teachers need to work collaboratively to encourage STEM career interest among students with disabilities in Nigeria and other countries. There should be a framework for awareness of students with disabilities about STEM career prospects and requirements. Reorientations and supporting persons with disabilities to excel in STEM field may be necessary for modeling. Students who are offered this information in school will be better able to make informed decisions about their interest in STEM and better prepare for those careers. Parents and teachers' negative and stereotvpical assumptions that lead to exclusion of students with disabilities from STEM fields should be countered. Attention should also be focused on turning and increasing students' beliefs about their capabilities to excel in STEM fields.

\section{REFERENCES}

1. Adelakun, S. A. (2017). An exploration and development of teaching resources to better include students with visual impairment in science and mathematics classes in South-Western Nigeria: An action research study [PhD Thesis]. University of Birmingham.

2. Renabeni T. Murry \& Lata Pujar, "Influence of Socioeconomic Status on Career Decision Making of Undergraduate Emerging Adults", International Journal of Educational Science and Research (IJESR), Vol. 7, Issue 5,pp, 55-62

3. Archer, L., DeWitt, J., Osborne, J., Dillon, J., Willis, B., \& Wong, B. (2012). Science aspirations, capital, and family habitus: How families shape children's engagement and identification with science. American Educational Research Journal, 49(5), $881-908$.

4. Sasmita Nayak, "Impact of Learning and Development StrategyOn Organisational Performance",International Journal of Business Management \& Research (IJBMR),Vol. 8, Issue 1,pp, 19-26

5. Aschbacher, P. R., Li, E., \& Roth, E. J. (2010). Is science me? High school students' identities, participation and aspirations in science, engineering, and medicine. Journal of Research in Science Teaching: The Official Journal of the National Association for Research in Science Teaching, 47(5), 564-582.

6. Isaac Zeb-Obipi, "Enhancing Corporate Productivity Performance Through Worker Competence Development",International Journal of Human Resources Management (IJHRM),Vol. 5, Issue 3,pp, 1-10

7. Brand, B., Valent, A., \& Danielson, L. (2013). Improving College and Career Readiness for Students with Disabilities. College and Career Readiness and Success Center.

8. Nuhu L. Garba \& Bashir Bukar, "Reforming Technical Vocational Education and Training for Peace and Development in Nigeria ",International Journal of Humanities and Social Sciences (IJHSS),Vol. 4, Issue 2,pp, 63-70

9. Burgstahler, S., \& Ladner, R. (2006). An alliance to increase the participation of individuals with disabilities in computing careers. ACM SIGACCESS Accessibility and Computing, 85, 3-9.

10. da Silva Cardoso, E., Dutta, A., Chiu, C., Johnson, E. T., Kundu, M., \& Chan, F. (2013). Social-cognitive predictors of STEM career interests and goal persistence in college students with disabilities from racial and ethnic minority backgrounds. Rehabilitation Research, Policy, and Education, 27(4), 271-284.

11. Dunn, C., Rabren, K. S., Taylor, S. L., \& Dotson, C. K. (2012). Assisting students with high-incidence disabilities to pursue careers in science, technology, engineering, and mathematics. Intervention in School and Clinic, 48(1), 47-54.

12. Dutta, A., Kang, H.-J., Kaya, C., Benton, S. F., Sharp, S. E., Chan, F., da Silva Cardoso, E., \& Kundu, M. (2015). SocialCognitive Career Theory predictors of STEM career interests and goal persistence in minority college students with disabilities: 
A path analysis. Journal of Vocational Rehabilitation, 43(2), 159-167.

13. Ebifa, S. E., Onuigbo, L. N., Onyechi, K. C. N., \& Egenti, N. (2018). Career Aspirations of Secondary School Students with Visual Impairment in Enugu State, Nigeria. 13(21), 6.

14. Estrada, M., Hernandez, P. R., \& Schultz, P. W. (2018). A longitudinal study of how quality mentorship and research experience integrate underrepresented minorities into STEM careers. CBE-Life Sciences Education, 17(1), ar9.

15. Gottfried, M. A., Bozick, R., Rose, E., \& Moore, R. (2016). Does career and technical education strengthen the STEM pipeline? Comparing students with and without disabilities. Journal of Disability Policy Studies, 26(4), 232-244.

16. Halim, L., Abd Rahman, N., Wahab, N., \& Mohtar, L. E. (2018). Factors influencing interest in STEM careers: An exploratory factor analysis. Asia-Pacific Forum on Science Learning and Teaching, 19(2), 1-34.

17. Izzo, M. V., Murray, A., Priest, S., \& McArrell, B. (2011). Using Student Learning Communities to Recruit STEM Students with Disabilities. Journal of Postsecondary Education and Disability, 24(4), 301-316.

18. Jenson, R. J., Petri, A. N., Day, A. D., Truman, K. Z., \& Duffy, K. (2011). Perceptions of self-efficacy among STEM students with disabilities. Journal of Postsecondary Education and Disability, 24(4), 269-283.

19. Joel, J. P. (2017). Influence of self-efficacy, academic self-concept and peer pressure on career decision making among secondary school students in Kenya.

20. Kauffmann, P., Hall, C., Batts, D., Bosse, M., \& Moses, L. (2009). Factors influencing high school students career considerations in STEM fields. ASEE Annual Conference and Exposition, Conference Proceedings, January.

21. Kier, M. W., Blanchard, M. R., Osborne, J. W., \& Albert, J. L. (2014). The development of the STEM career interest survey (STEM-CIS). Research in Science Education, 44(3), 461-481.

22. Kimani, G. N., Kara, A. M., \& Njagi, L. W. (2013). Teacher Factors Influencing Students' Academic Achievement in Secondary Schools.

23. Lee, A. (2011a). A comparison of postsecondary science, technology, engineering, and mathematics (STEM) enrollment for students with and without disabilities. Career Development for Exceptional Individuals, 34(2), 72-82.

24. Lee, A. (2011b). A comparison of postsecondary science, technology, engineering, and mathematics (STEM) enrollment for students with and without disabilities. Career Development for Exceptional Individuals, 34(2), 72-82.

25. Lee, A. (2014). Students with Disabilities Choosing Science Technology Engineering and Math (STEM) Majors in Postsecondary Institutions. Journal of Postsecondary Education and Disability, 27(3), 261-272.

26. Maltese, A. V., \& Tai, R. H. (2011). Pipeline persistence: Examining the association of educational experiences with earned degrees in STEM among US students. Science Education, 95(5), 877-907.

27. McDonald, K. S., \& Waite, A. M. (2019). Future directions: Challenges and solutions facing career readiness and development in STEM fields. Advances in Developing Human Resources, 21(1), 133-138.

28. McGunagle, D., \& Zizka, L. (2020). Employability skills for 21st-century STEM students: The employers' perspective. Higher Education, Skills and Work-Based Learning.

29. Mcmahon, B. T. (2013). Adolescence to adulthood in STEM education and career development: The experience of students at the intersection of underrepresented minority status and disability. December. https://doi.org/10.3233/JVR-130655

30. Onyishi, C. N., \& Sefotho, M. M. (n.d.). Mathematics Self-efficacy as a Predictor of Science Technology Engineering and Mathematics (STEM) Career Inclination among Secondary School Students with Disabilities. 
31. Onyishi, C. N., \& Sefotho, M. M. (2019). Mathematics Self-Efficacy as a Predictor of Science Technology Engineering and Mathematics ( Stem ) Career Inclination among Secondary School Students with. International Journal of U-and-E Research, $12(4), 1-14$

32. Osokoya, M. M., \& Junaid, I. O. (2015). Enrolment and achievement of persons with special education needs in secondary schools in science subjects: Facts and patterns. Journal of Education, Society and Behavioural Science, 137-149.

33. Peng, H. H., Johanson, R. E., \& Chang, M.-H. (2012). Career indecision and state anxiety of returned international Chinese undergraduate students in Taiwan. International Journal of Psychology and Counselling, 4(9), 106-114.

34. Quinter, M., \& Edwards, K. (2011). Factors influencing students career choices among secondary school students in Kisumu municipality, Kenya. Journal of Emerging Trends in Educational Research and Policy Studies, 2(2), 81-87.

35. Rule, A. C., Stefanich, G. P., Haselhuhn, C. W., \& Peiffer, B. (2009). A Working Conference on Students with Disabilities in STEM Coursework and Careers. Online Submission

36. Schreffler, J., Vasquez III, E., Chini, J., \& James, W. (2019). Universal design for learning in postsecondary STEM education for students with disabilities: A systematic literature review. International Journal of STEM Education, 6(1), 8

37. Tillman, K. (2015). Parental influence on college students' career aspirations

38. Tuijl, C. Van, \& Van, J. H. W. (2016). Study choice and career development in STEM fields: An overview and integration of the research. International Journal of Technology and Design Education, 26(2), 159-183. https://doi.org/10.1007/s10798-0159308-1

39. van Tuijl, C., \& van der Molen, J. H. W. (2016). Study choice and career development in STEM fields: An overview and integration of the research. International Journal of Technology and Design Education, 26(2), 159-183.

40. Waite, A. M., \& McDonald, K. S. (2019). Exploring Challenges and Solutions Facing STEM Careers in the 21st Century: A Human Resource Development Perspective. Advances in Developing Human Resources, 21(1), 3-15. https://doi.org/10.1177/1523422318814482

41. Yerdelen, S., Kahraman, N., \& Yasemin, T. (2016). Low socioeconomic status students' STEM career interest in relation to gender, grade level, and STEM attitude. Journal of Turkish Science Education, 13(special), 59-74.

42. Holman, J., \& Finegold, P. (2010). STEM Careers Review. Report to the Gatsby Charitable Foundation. Retrieved from https:// warwick.ac.uk/fac/soc/ier/ngrf/stem/movingon/research/500stem_careers_review_nov_2010_holman.pdf

43. Wyss, V. L., Heulskamp, D., \& Siebert, C. J. (2012). Increasing middle school student interest in STEM careers with videos of scientists. International Journal of Environmental and Science Education, 7(4), 501-522.

44. Franz-Odendaal, T. A., Blotnicky, K., French, F., \& Joy, P. (2016). Experiences and perceptions of STEM subjects, careers, and engagement in STEM activities among middle school students in the maritime provinces. Canadian Journal of Science, Mathematics and Technology Education, 16(2), 153-168

45. Jenson, R. J., Petri, A. N., Day, A. D., Truman, K. Z., \& Duffy, K. (2011). Perceptions of self-efficacy among STEM students with disabilities. Journal of Postsecondary Education and Disability, 24(4), 269-283. 